\title{
CREATION AND DEVELOPMENT OF THE NATIONAL HUMIDITY STANDARD OF GASES
}

\author{
Efimia LUCHIAN, Constantin BORDIANU, Grigore BUZUC, Victoria CEBAN \\ National Institute of Metrology, Chisinau, Republic of Moldova \\ tel.: (+373) 22903142 \\ e-mail: luchian.efimia@metrologie.md
}

\begin{abstract}
Summary: Creation and research of national humidity standard of gases unit is a part of the program of metrology infrastructure development, approved by the Government of Moldova. It is one of the prime steps in ensuring the uniformity of measurements in the country since in the Republic of Moldova was a lack of standard base in this field of measurements. As a result, economic agents were forced to invest more in the measurement provided in other countries, which inevitably led to higher costs for maintaining quality of the domestic production. In this paper, the principle of the realization of humidity unit gases and further transfer to measuring instruments are described. For the qualitative implementation of the foregoing, the main components of the measurement uncertainty are presented.
\end{abstract}

\section{INTRODUCTION}

Humidity measurement is an important part of many fields of national economy, such as:

- $\quad$ wood industry (monitoring of drying process of wood and wood products);

- $\quad$ food industry;

- $\quad$ agro-industrial sector (in order to know: the irrigation rational soil moisture, humidity of cereals for a better harvesting and storage timing, humidity of industrial plants etc.)

- $\quad$ trade activity (import, export);

- $\quad$ biology and medicine (germination, fermentation, diagnosis, treatment);

- $\quad$ pharmaceutical industry [1].

In order to reduce the negative impact of humidity on the economy sectors of Republic of Moldova we need to know humidity values with a high degree of certainty. This requires a national standard for gases humidity which will be able to collect, preserve and transmit the measurement unit of humidity. Creation, research and development of the national standards is a primary function of the National Institute of Metrology (NIM). At the same time, it is responsible for the transmission of measurement unit towards the measuring instruments used by economic agents from Moldova.

Another very important aspect is to ensure the uniformity for gas humidity measurement respecting the traceability of the national measurement unit to primary international standards, and finally, to SI units ( $\mathrm{K} \mathrm{Pa}$ ) [2]. This is necessary in order to give to the economic entities the opportunity to perform the calibration of measuring instruments in the Republic of Moldova, and in such way to reduce costs.

The hierarchy of humidity standards is presented in Figure 1.

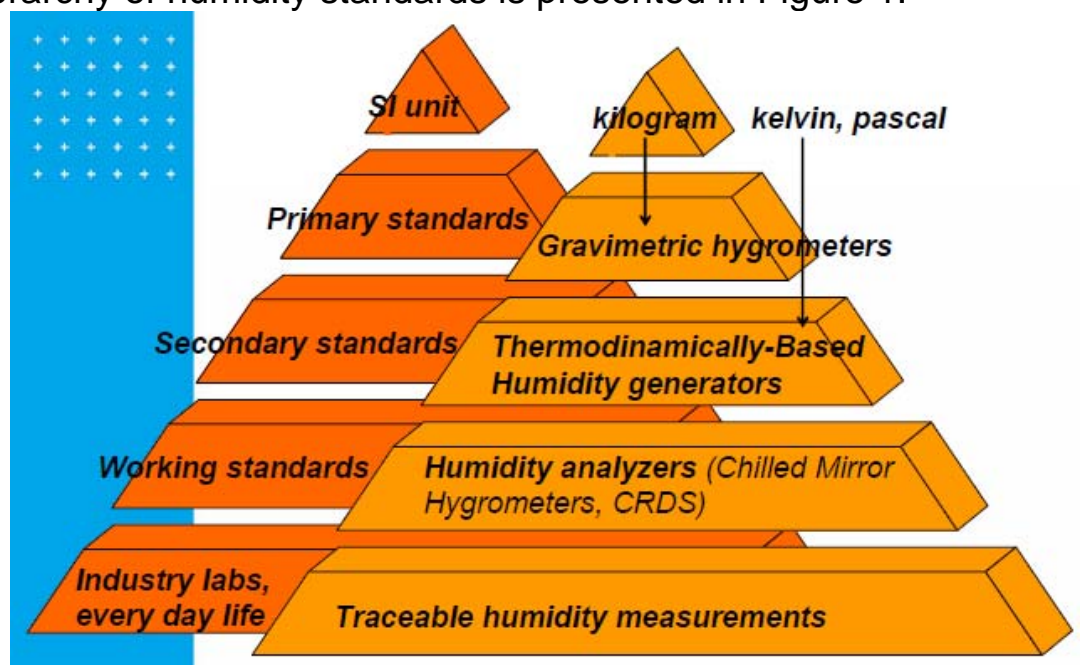

Figure 1. The hierarchy of humidity standards 


\section{NATIONAL HUMIDITY STANDARD OF GASES (NHSG)}

During the selection process of the proper equipment needed for creation of NHSG several important factors have been taken into account, such as:

- Measurement accuracy required by economic entities, in order to satisfy the country's needs;

- Scientific and technical progress in the field;

- The practice of other countries in creating national standards;

- Technical and economic arguments.

Since Moldova is party to various international professional organizations, including the Interstate Council for Standardization, Metrology and Certification (EASC), the requirements specified in the interstate document GOST 8.457-2009 "State system for ensuring the uniformity of measurements. State verification schedule for means measuring humidity of gases" [3] were taken into account. NIM is currently registered in the key comparison of the regional organization COOMET, entitled 544/RU/11 „Regional comparison humidity standards of gases. Dew/frost point temperature $-50^{\circ} \mathrm{C}$ to $+20^{\circ} \mathrm{C}$ " [4].

As a result the following equipments have been purchased:

1. Humidity Generator, model 2500ST produced by Thunder Scientific (Figure 2), which is an automated system able to reproduce various values of humidity, in a wide range of temperatures, and will be used for the calibration of measuring means of both the relative humidity of the air, and temperature.

2. Dew point standard hygrometer, model Dew Point Mirror $373 \mathrm{H}$, produced by MBW, Switzerland (Figure 3).

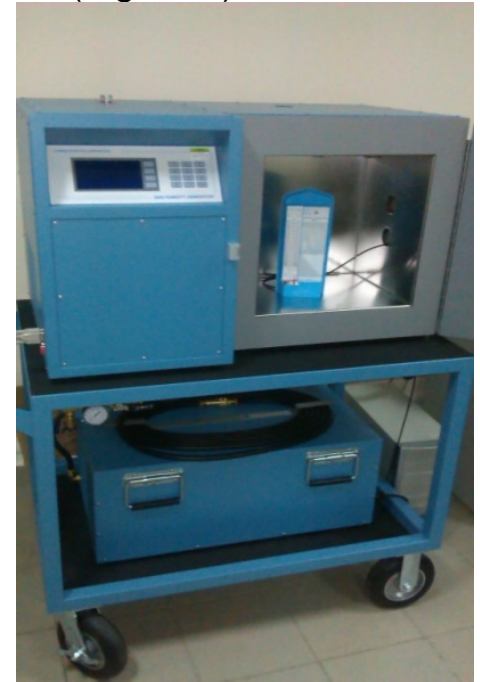

Figure 2. Humidity generator, model 2500ST

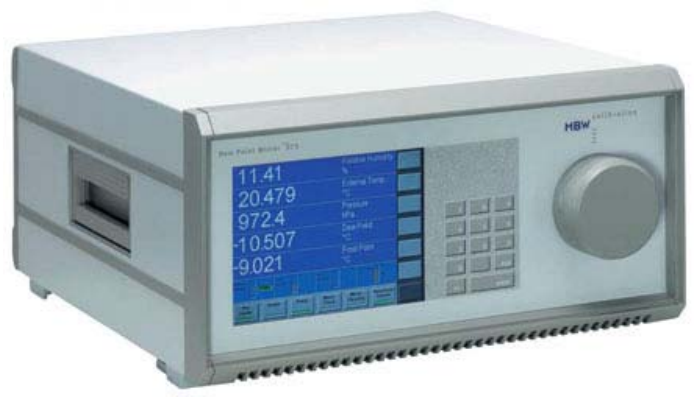

Figure 3. Dew point standard hygrometer, model Dew Point Mirror 373H

Technical and metrological characteristics of Humidity generator, model 2500ST, and Dew point standard hygrometer, model Dew Point Mirror $373 \mathrm{H}$, are given in Table 1 and Table 2, respectively.

Table 1. Technical and metrological characteristics of Humidity generator, model 2500ST

\begin{tabular}{|l|c|}
\hline Relative humidity range & $10 \div 95 \%$ \\
\hline Relative humidity display resolution & $0.02 \%$ \\
\hline Relative humidity uncertainty & $0.5 \% \mathrm{RH}$ \\
\hline Chamber temperature range & $-10 \div 70^{\circ} \mathrm{C}$ \\
\hline Temperature display resolution & $0.02^{\circ} \mathrm{C}$ \\
\hline Chamber temperature uniformity & $0.1^{\circ} \mathrm{C}$ \\
\hline Chamber temperature uncertainty & $0.06^{\circ} \mathrm{C}$ \\
\hline Chamber pressure uncertainty & $0.15 \%$ \\
\hline
\end{tabular}

Hygrometer Model $373 \mathrm{H}$ fulfills the best performance achieved in the humidity measurement. It is based on optical detection technology of the condensing moment on the cooled mirror. 
Table 2. Technical and metrological characteristics of Dew point standard hygrometer, model Dew Point Mirror 373H

\begin{tabular}{|l|c|}
\hline Dew point measuring range & $(-30 \div 70)^{\circ} \mathrm{C}$ \\
\hline Relative humidity measuring range & $0.5 \div 100 \%$ \\
\hline Dew point accuracy & $\pm 0.1^{\circ} \mathrm{C}$ \\
\hline Dew point reporductibility & $\pm 0.05^{\circ} \mathrm{C}$ \\
\hline Mirror cooling & $0.04^{\circ} \mathrm{C}$ \\
\hline Measuring uncertainity & 3-stage Peltier thermoelectric \\
\hline
\end{tabular}

In order to minimize the influence of the human factor and, to increase the accuracy of measurement, the laboratory is equipped with specialized software applications capable to minimize the operator's intervention.

\section{THE METHOD OF REALIZATION THE HUMIDITY UNIT OF GASES}

Realization of the gas humidity unit is based on the two-pressure method of producing known atmospheres of relative humidity and assumes that the water vapor pressure remains a fraction of the total pressure, known as Dalton's Law of Partial Pressure. Dalton's Law states that the pressure exerted by a mixture of gases in a given volume at some temperature is equal to the sum of the pressures which would be exerted by each individual gas if it alone occupied the volume at the same temperature [5].

where:

$$
P=p_{1}+p_{2}+\ldots+p_{n}
$$

$p_{1}, p_{2}, p_{n}$ - partial pressures of each component.

The two pressure method (shown in elemental schematic form in figure 4) involves saturating air, or some other gas such as nitrogen, with water vapor at a given pressure and temperature. The saturated gas then flows through an expansion valve where it is isothermally reduced to chamber pressure. If the temperature of the gas is held constant during pressure reduction, the humidity, at chamber pressure, may then be approximated as the ratio of two absolute pressures.

$$
R H \% \approx \frac{P_{\text {chamber }}}{P_{\text {saturator }}} .100
$$

Humidity produced in the test chamber of this system does not depend on devices such as psychrometers, dew point hygrometers, or solid state sensors for the measurement of water vapor content. Humidity that is produced is solely dependent on the measurement of absolute pressures and on the maintenance of isothermal conditions. Precision humidity generation is determined by the accuracy of these pressure measurements and uniformity of temperature throughout the generating system [6].

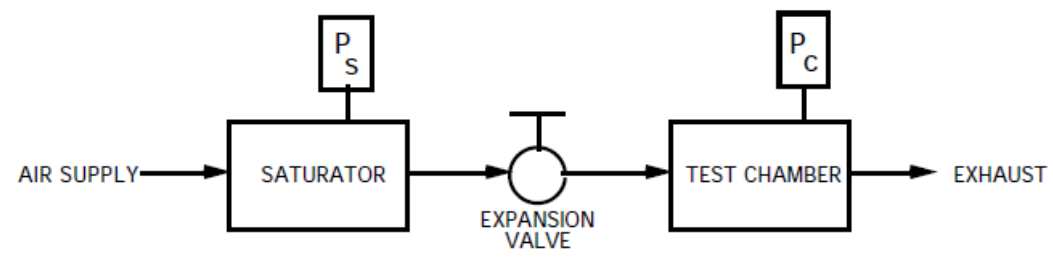

Figure 4. Elemental schematic form of the two pressure method

\section{ESTIMATION OF UNCERTAINTY OF MEASUREMENT}

Measurement uncertainty estimation is carried out in accordance with SM SR ISO/CEI Guide 98-3:2011 [7] and it is quite difficult due to both the large number of influential factors and complexity of determining relations for humidity unit. For example, the mathematical model for uncertainty estimation in the case of dew or frost point temperature measurements can be expressed by next equation:

$$
u^{2}\left(t_{d}\right)=\left(\frac{\partial t_{d}}{\partial t_{s}}\right)^{2} \cdot u^{2}\left(t_{s}\right)+\left(\frac{\partial t_{d}}{\partial P_{s}}\right)^{2} \cdot u^{2}\left(P_{s}\right)+\left(\frac{\partial t_{d}}{\partial P_{c}}\right)^{2} \cdot u^{2}\left(P_{c}\right)+\left(\frac{\partial t_{d}}{\partial \eta_{s}}\right)^{2} \cdot u^{2}\left(\eta_{s}\right)+u^{2}\left(t_{d \text { mas }}\right)
$$


Dew/frost point can be determined from the following relation:

$$
e_{w}\left(t_{d}\right)=e_{s}\left(t_{s}\right) \cdot \frac{f\left(t_{s}, P_{s}\right)}{f\left(t_{d}, P_{c}\right)} \cdot \frac{P_{c}}{P_{s}} \cdot \eta_{s}
$$

Where:

$f\left(t_{s}, P_{s}\right), f\left(t_{c}, P_{c}\right)$ - multiplication factors evaluated at saturation temperature and pressure, and chamber temperature and pressure, respectively;

$e_{s}$ - saturation vapor pressure;

$e_{w}-$ saturation vapor pressure over water;

$e_{g}-$ saturation vapor pressure over ice;

$\eta_{s}$ - saturation efficiency;

$t_{d}, t_{f}, t_{c}, t_{s}-$ dew/frost point temperature from chamber and saturator;

$P_{c}, P_{s}-$ chamber and saturator pressures.

In this case, uncertainty components related to dew/frost point generation are due to saturator and chamber pressures, saturator temperature and efficiency. For example, the uncertainty due to the saturator temperature $u\left(t_{s}\right)$ will be:

$$
u_{c}^{2}\left(t_{s}\right)=u^{2}\left(\delta t_{s}\right)+u^{2}\left(\delta t_{s d r i f t}\right)+u^{2}\left(\delta t_{s \text { rez }}\right)+u_{r}^{2}(e)+u^{2}\left(t_{s \text { eff }}\right)
$$

$\delta t_{s}$ is the contribution given by the calibration of temperature transducer of the saturator:

$$
\delta t_{s}=\frac{U_{t s}}{2}
$$

$U_{t s}$ - expanded uncertainty (for $k=2$ ), from the calibration certificate.

Contribution given by the temporal drift of the temperature transducer of the saturator $\delta t_{s}$ drift. The deviation of the indication as against to the last calibration is estimated from calibration history. This temporal drift $\left(d_{t s}\right)$ cannot be used as a correction, but may be taken into account in the uncertainty evaluation. The standard uncertainty of this rectangular distribution is:

$$
u\left(\delta t_{\text {sdrift }}\right)=\frac{d_{t s}}{\sqrt{3}}
$$

Contribution given by the temperature transducer resolution $-\delta t_{s}$ rez. The associated uncertainty of this rectangular distribution is:

$$
u\left(\delta t_{\text {srez }}\right)=\frac{d_{\text {tsrez }}}{2 \cdot \sqrt{3}}
$$

The uncertainty due to the equation for vapor pressure calculation $-u_{r}(e)$. Pressures $e_{s}$ and $e_{c}$ represents the pressures of saturated vapors calculated, using the equation Hardy [8], at saturator and chamber temperature, respectively.

$$
e_{s}=\exp \left(\sum_{i=0}^{6} a_{i} \cdot T^{i-2}+a_{7} \cdot \ln T\right)
$$

where $\mathrm{T}=\mathrm{t}+273.15$ represents the temperature in $K ; a_{i}$ - interpolation coefficients according to Hardy relation.

Ideally, in the generators based on "two pressure" principle, the saturator and chamber temperatures are identic, and the saturation pressure ratio $e_{s} / e_{c}=1$. However, in a real system, there is a little difference between these two temperatures, and they should be measured. The associated uncertainty due to calculation of vapor pressure using this relation is:

$u_{r}(e)=0,005 \%$, in the temperature range between $0^{\circ} \mathrm{C}$ and $100^{\circ} \mathrm{C}$,

$u_{r}(e)=(0,01-0,005 \cdot t) \%$, in the temperature range between $-100^{\circ} \mathrm{C}$ and $0^{\circ} \mathrm{C}$.

$u\left(t_{s}\right.$ eff $)$ - uncertainty due to saturation efficiency. In relation (2) $t_{s}$ is dew temperature at pressure $P_{s}$ at saturator outlet. Actually the value is influenced by the temperature of the fluid, which in the pre-saturator (before the saturator inlet) is preconditioned to a temperature higher than the dew point. The associated uncertainty due to the efficiency of the saturator takes into account the difference between the temperature of the fluid $t_{f}$ and $t_{s}$ resulting by saturated air flow at temperatures higher (or lower) than the condensate. The humidity generators, based on the two pressures principle, are based on the complete saturation capacity of the gas with water vapor, during its passage from the inlet to the outlet of the 
saturator. Saturation efficiency is estimated to be $100 \pm 0.35 \%$. The standard associated uncertainty of this triangular distribution is:

$$
u\left(t_{\text {seff }}\right)=\frac{0,35}{\sqrt{6}}
$$

At the same time, some components of the mathematical model are dependent on other influencing sizes, fact that further complicates the estimation of measurement uncertainty.

\section{CONCLUSIONS}

Creation, research and development of the national standards is a primary function of any Institute of Metrology and at the same time, the primary condition for the full implementation of the unity of measurements in the country. The national standard of gas humidity unit is intended for the realization, storage and transfer of the unit through working standards to measuring instruments used in the national economy. As a result of participation in the international comparisons within regional organizations COOMET, the National Institute of Metrology from Republic of Moldova will demonstrate its measurement capabilities. Thus, both the national standard and humidity measurements provided in the Republic of Moldova will be recognized at regional and international levels. This fact will help to remove technical barriers to trade encountered by economic agents from Moldova.

\section{BIBLIOGRAPHY}

[1] Bordianu Constantin, The importance of creation of national standard unit for humidity, Metrologie, Vol.1 (7)/2013, p 9-12.

[2] SM SR Ghid ISO/CEI 99:2012 "Vocabulary of Metrology. Basic and General Concepts and Associated Terms (VIM)"

[3] GOST 8.457-2009 „State system for ensuring the uniformity of measurements. State verification schedule for means measuring humidity of gases"

[4] http://www.coomet.org/DB/com/index.htm?EN,PRJ_EN,EN/CMPR

[5] The Rotronic Humidity Handbook, 2005 Rotronic Instrument Corp.

[6] Thunder Scientific Corporation, Operation and maintenance manual for Series 2500 benchtop two-pressure humidity generator, 623 Wyoming S.E. Albuquerque, New Mexico 87123-3198, 2003, edition 4, p 106.

[7] SM SR Ghid ISO/CEI 98:2011 „Uncertainty of measurement. Part 3. Guide to the expression of uncertainty in measurement"

[8] R. Hardy, Papers and Abstracts of the Third International Symposium on Humidity and Moisture, April 1998, vol. 1, pp. 214-222,. 